\title{
Pollution, ecological-health risks, and sources of heavy metals in soil of the northeastern Qinghai-Tibet Plateau
}

\author{
Jun $\mathrm{Wu}^{\mathrm{a}, \mathrm{b}}$, Jian $\mathrm{Lu}^{\mathrm{c},{ }^{*}}$, Leiming $\mathrm{Li}^{\mathrm{a}}{ }^{\mathrm{b}}$, Xiuyun Min ${ }^{\mathrm{a}, \mathrm{b}}$, Yongming Luo ${ }^{\mathrm{c}}$ \\ ${ }^{a}$ Key Laboratory of Comprehensive and Highly Efficient Utilization of Salt Lake Resources, Qinghai Institute of Salt Lakes, Chinese Academy of Sciences, \\ Xining, Qinghai 810008, China \\ ${ }^{\mathrm{b}}$ Qinghai Provincial Key Laboratory of Geology and Environment of Salt Lakes, Xining, Qinghai 810008, China \\ ${ }^{\mathrm{c}}$ Key Laboratory of Coastal Environmental Processes and Ecological Remediation, Yantai Institute of Coastal Zone Research, Chinese Academy of Sciences, \\ Yantai, Shandong 264003 China
}

\section{H I G H L I G H T S}

- Serious soil heavy metal pollution occurred in the study area.

- The study area showed high ecological risks posed by soil heavy metals.

- Cancer risks of heavy metals were high, especially for children.

- Non-cancer risks of heavy metals for children were high.

- Industrial activities might be the main source for heavy metals in soil.

\section{A R T I C L E I N F O}

\section{Article history:}

Received 27 October 2017

Received in revised form

6 February 2018

Accepted 20 February 2018

Available online 21 February 2018

Handling Editor: Jian-Ying Hu

\section{Keywords:}

Heavy metal

The Qinghai-Tibet plateau

Ecological risk

Health risk

Source apportionment
G R A P H I C A L A B S T R A C T

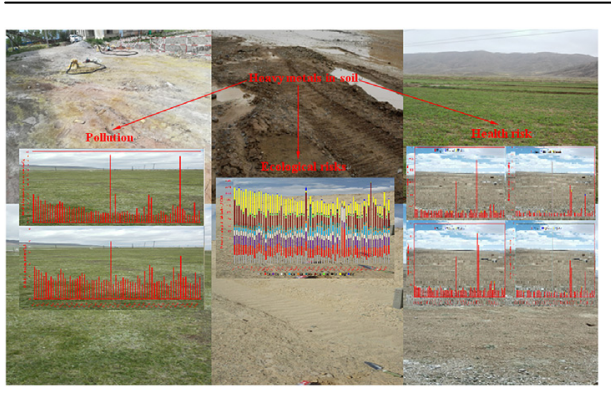

\section{A B S T R A C T}

The Qinghai-Tibet Plateau, especially the northeastern region, is not a pure land any more due to recently increasing anthropogenic activities. This study collected soil samples from 70 sites of the northeastern Qinghai-Tibet Plateau to evaluate pollution, ecological-health risks, and possible pollution sources of heavy metals. The concentrations of heavy metals in soil were relatively high. Values of geoaccumulation index exhibited that $\mathrm{Hg}$ pollution was the most serious meanwhile $\mathrm{Hg}$ possessed the strongest enrichment feature based on enrichment factor values. The modified degrees of contamination showed that about $54.3 \%$ and $17.1 \%$ of sampling sites were at moderate and high contamination degree while pollution load indexes illustrated that $72.9 \%$ and $27.1 \%$ of sampling sites possessed moderate and high contamination level, respectively. Ecological risk indexes of heavy metals in soil ranged from 234.6 to 3759.0, suggesting that most of sites were under considerable/very high risks. Cancer risks for adults and children were determined as high and high-very high levels while non-cancer risks for children were high although those for adults were low. Industrial source contributed to the main fraction of ecological and health risks. Summarily speaking, heavy metals in soil of the study area has caused significantly serious pollution and exerted high potential ecological and health risks, especially for children who are more susceptible to hurt from pollutants. Therefore, more efficient and strict pollution control and management in study area should be put out as soon as possible.

๑) 2018 Elsevier Ltd. All rights reserved.

\footnotetext{
* Corresponding author

E-mail address: jlu@yic.ac.cn (J. Lu).
} 


\section{Introduction}

Soil, an important sink of nutrients and pollutants, plays critical function in social-ecological stability and safety. However, soil pollution has become an important obstacle for regional development and human health in recent decades (Jiang et al., 2017; Liang et al., 2017; Padoan et al., 2017; Pan et al., 2016; Peng et al., 2017; Sakai et al., 2017). Heavy metals, defined as metals or metalloids with a specific density larger than $5 \mathrm{~g} / \mathrm{cm}^{3}$ (Järup, 2003; Oves et al., 2012), have become an important kind of pollutants in soil all over the world (Kowalska et al., 2016; Rachwał et al., 2017; Tepanosyan et al., 2017a; Tian et al., 2016; Wu et al., 2016a).

Originated from natural and anthropogenic sources, heavy metals possess acute and chronic toxicity, environmental persistence, and bioaccumulation to exert potential risks to the ecosystem and human health (Burges et al., 2015; Jiang et al., 2017; Salmanighabeshi et al., 2015; Zhu et al., 2017). Therefore, more research starts focusing on the ecological and health risks of heavy metals besides their distribution and pollution (Jiang et al., 2017; Peng et al., 2017; Tepanosyan et al., 2017a, 2017b; Xiao et al., 2017; Zhu et al., 2017). Moreover, multiple methods such as geoaccumulation index $\left(I_{g e o}\right)$, modified degree of contamination $\left(m C_{d}\right)$, enrichment factor $(E F)$, and pollution load index $(P L I)$ have been employed to comprehensively evaluate the heavy metal pollution in soil (Ćujić et al., 2016; Tian et al., 2017; Zhu et al., 2017). Furthermore, source apportionment of heavy metals in soil also attracts increasing attention (Jiang et al., 2017; Peng et al., 2017).

The Qinghai-Tibet Plateau, generally regarded as the pure land, has exhibited unexpected heavy metal pollution (Bing et al., 2014; Huang et al., 2008; Sheng et al., 2012; Wu et al., 2016a; Yang et al., 2007, 2011; Zhang et al., 2013). Heavy metals were frequently detected in biota of the Qinghai-Tibet Plateau with the highest $\mathrm{Pb}$ concentrations in fish/plant samples of $0.079 / 62.1 \mathrm{mg} / \mathrm{kg}$ and the maximal $\mathrm{Hg}$ concentration in fish samples of $2384 \mu \mathrm{g} / \mathrm{kg}$, respectively (Bing et al., 2014; Yang et al., 2007, 2011). Heavy metals were also widely detected in different environmental matrices with the highest $\mathrm{Pb} / \mathrm{Cr}$ concentrations in soil and water samples of 1075.69/ $3429.00 \mathrm{mg} / \mathrm{kg}$ and $781 / 2.74 \mu \mathrm{g} / \mathrm{L}$, respectively (Huang et al., 2008; Sheng et al., 2012; Zhang et al., 2013). Therefore, heavy metal pollution in the Qinghai-Tibet Plateau should not be neglected. However, it is regretful that the previous studies have not illustrated the thorough information on the pollution, ecological and health risks, and source identification of heavy metals in soil of the Qinghai-Tibet Plateau, especially in the northeastern part that is the area with the most extensive anthropogenic disturbance of the whole plateau. Therefore, this study adopted different methods to assess the pollution, ecological-health risks, and source of heavy metals in soil of the northeastern Qinghai-Tibet Plateau. The objectives of this study are to provide complete and comprehensive information on heavy metals in soils of the northeastern QinghaiTibet Plateau and lay a basis for the soil pollution prevention and control of the high-elevation areas.

\section{Materials and methods}

\subsection{Study area, sampling strategy, and detection methods}

The study area locates in the northeastern Qinghai-Tibet Plateau. Field sampling was performed during May 31th to June 13th, 2016. Total 70 topsoil $(0-20 \mathrm{~cm})$ samples were collected (Fig. S1), covering the main industrial, mining, and agricultural zones and main traffic lines of the study area. The samples were in situ homogenized and stored in the sample bags until back to the laboratory. The soil samples were air dried at the room temperature, and then passed through $0.074 \mathrm{~mm}$ sieve for chemical analysis.

Soil $\mathrm{pH}$ was determined with the supernatants of water-soil ratio of 2.5:1 using a pH meter (Shanghai INESA Scientific Instrument Co., China). Soil total organic carbon (TOC) was measured by a multi N/C 3100 analyzer (Analytik Jena AG, Germany). Microwavedigested soil samples were analyzed by an Agilent7900 inductively coupled plasma mass spectrometry (ICP-MS, Agilent Inc, USA). Concentrations of 12 typical heavy metals including vanadium $(\mathrm{V})$, chromium $(\mathrm{Cr})$, cobalt $(\mathrm{Co})$, nickel $(\mathrm{Ni})$, copper $(\mathrm{Cu})$, zinc $(\mathrm{Zn})$, molybdenum (Mo), cadmium ( $\mathrm{Cd}$ ), tin ( $\mathrm{Sn}$ ), antimony (Sb), mercury $(\mathrm{Hg})$, and lead $(\mathrm{Pb})$ were determined.

\subsection{Evaluation on soil heavy metal pollution}

Four methods including $I_{g e o}, E F, m C_{d}$, and $P L I$ were adopted to evaluate the soil heavy metal pollution. Proposed by Müller (1969) and defined as the following, $I_{\text {geo }}$ generally exhibits the pollution intensity of individual heavy metal.

$I_{g e o}=\log _{2} \frac{C_{x}^{i}}{1.5 \times C_{b}^{i}}$

where $C_{x}^{i}$ and $C_{b}^{i}$ refer to the concentration of the $i$ th heavy metal in the soil sample and its background concentration in soil that referred to MEPC (1990), respectively.

$E F$ is mainly used to quantify anthropogenic influences on heavy metal pollution (Chester and Stoner, 1973; Clark et al., 2014; Zhu et al., 2017), defined as the following:

$E F=\frac{\left(\frac{C_{x}^{i}}{R_{\text {soil }}}\right)}{\left(\frac{C_{b}^{i}}{R_{b}}\right)}$

where $R_{\text {soil }}$ and $R_{b}$ represent the reference element concentration in soil sample and background soil, respectively. Elements Ti, Al, Fe, $\mathrm{Mn}, \mathrm{Sc}$ or Ca can generally serve as acceptable $E F$ reference element (Salmanighabeshi et al., 2015). This study used Ti as reference element considering that its contents in soil were relatively high and determined accurately by ICP-MS.

$P L I$ and $m C_{d}$ are comprehensive indexes to characterize the pollution degree by all target heavy metals. $m C_{d}$ is defined by the following equation (Abrahim and Parker, 2008; Wu et al., 2016a).

$m C_{d}=\frac{\sum_{i=1}^{n} \frac{C_{x}^{i}}{C_{b}^{i}}}{n}$

where $n$ refers to the number of pollutants.

PLI is determined as follows (Bhuiyan et al., 2010; Ćujić et al., 2016; Tian et al., 2017):

$P L I=\left(\frac{C_{\chi}^{1}}{C_{b}^{1}} \times \frac{C_{\chi}^{2}}{C_{b}^{2}} \times \ldots \times \frac{C_{\chi}^{n}}{C_{b}^{n}}\right)^{\frac{1}{n}}$

\subsection{Ecological risks of soil heavy metals}

Potential ecological risk index (PERI) is a factor to comprehensively assess the potential ecological risks posed by heavy metals in soil/sediment (Hakanson, 1980; Ke et al., 2017; Madiseh et al., 2009). PERI is calculated using the following equation: 
PERI $=\sum_{i=1}^{n} T_{x}^{i} \times \frac{C_{x}^{i}}{C_{b}^{i}}$

where $T_{x}^{i}$ means the biological toxicity factor of an individual heavy metal, which is determined as $\mathrm{Cr}=2, \mathrm{Ni}=\mathrm{Cu}=\mathrm{Pb}=5, \mathrm{Zn}=1$, and $\mathrm{Hg}=40$ (Ke et al., 2017; Hakanson, 1980; Tian et al., 2017). $T_{x}^{i}$ values for $\mathrm{V}, \mathrm{Mo}, \mathrm{Sn}$, and $\mathrm{Sb}$ were determined according to Hakanson (1980).

\subsection{Health risks of soil heavy metals}

Health risks of heavy metals in soil of the northeastern QinghaiTibet Plateau were evaluated using cancer risks and non-cancer risks through three pathways including ingestion, dermal contact, and inhalation of soil particles (Ferreira-Baptista and De Miguel, 2005; Jiang et al., 2017; Peng et al., 2017; USEPA, 2016; Wu et al., 2016b). Non-cancer risks were evaluated using hazard quotients.

The cancer risks and hazard quotients of the pollutants through ingestion, dermal contact, and inhalation of soil particles are calculated using the following equations (Jiang et al., 2017; Peng et al., 2017; Rovira et al., 2010; Sultana et al., 2014; USEPA, 2016):

$$
\begin{aligned}
C R_{\text {ingest }}= & \frac{C_{\text {soil }} \times I n g R \times E F_{e} \times E D_{e}}{B W \times A T} \times C F \times S F \\
H Q_{\text {ingest }}= & \frac{C_{\text {soil }} \times I n g R \times E F_{e} \times E D_{e}}{B W \times A T \times R f D_{\text {ing }}} \times C F \\
C R_{\text {dermal }}= & \frac{C_{\text {soil }} \times S A \times A F_{\text {soil }} \times A B S \times E F_{e} \times E D_{e}}{B W \times A T} \times C F \times S F \\
& \times \text { GIABS }
\end{aligned}
$$$$
H Q_{\text {dermal }}=\frac{C_{\text {soil }} \times S A \times A F_{\text {soil }} \times A B S \times E F_{e} \times E D_{e}}{B W \times A T \times R f D_{\text {der }}} \times C F \times G I A B S
$$$$
C R_{\text {inhale }}=\frac{C_{\text {soil }} \times \operatorname{InhR} \times E F_{e} \times E D_{e}}{P E T \times B W \times A T} \times S F
$$$$
H Q_{\text {inhale }}=\frac{C_{\text {soil }} \times I n h R \times E F_{e} \times E D_{e}}{P E T \times B W \times A T \times R f D_{\text {inh }}}
$$$$
C R=C R_{\text {ingest }}+C R_{\text {dermal }}+C R_{\text {inhale }}
$$

$H Q=H Q_{\text {ingest }}+H Q_{\text {dermal }}+H Q_{\text {inhale }}$

where $C R_{\text {ingest }} / C R_{\text {dermal }} / C R_{\text {inhale }}$ refers to cancer risk via accidental ingestion of soil/dermal contact of soil/inhalation of soil; HQingest/ $H Q_{\text {dermal }} / H Q_{\text {inhale }}$ refers to hazard quotient via accidental ingestion of soil/dermal contact of soil/inhalation of soil; $C_{\text {soil }}$ refers to the concentration of pollutant in soil $(\mathrm{mg} / \mathrm{kg}) ; \mathrm{Ing} R$ is the ingestion rate of soil (values referred to USEPA, 2016); $E F_{e}$ is soil exposure frequency ( $350 \mathrm{~d} / \mathrm{yr}$ based on USEPA, 2016); $E D_{e}$ is exposure duration ( 6 years for children and 26 years for adults based on USEPA, 2016); $C F$ is the average conversion factor $\left(1 \times 10^{-6} \mathrm{~kg} / \mathrm{mg}\right.$ based on USEPA, 2016); $B W$ refers to body weight ( $\mathrm{kg}$, children: $B W=15$, adults: $B W=60$ ); $A T$ is average time (values for children and adults referred to USEPA, 2016); SA refers to surface area of the skin (values for children and adults referred to USEPA, 2016); $A F_{\text {soil }}$ refers to the skin adherence factor for soil $\left(0.2 \mathrm{mg} / \mathrm{cm}^{2}\right) ; A B S$ is the dermal absorption factor (chemical specific, obtained from USEPA, 2016); GIABS is the fraction of pollutant absorbed in gastrointestinal tract (set at 1 based on USEPA, 2016); PEF is the particle emission factor $\left(1.36 \times 10^{9} \mathrm{~m}^{3} / \mathrm{kg}\right) ; S F$ refers to cancer slope factor $(\mathrm{kg} \cdot \mathrm{d} / \mathrm{mg})$; $R f D_{\text {ing, }} R f D_{\text {ider, }}$ and $R f D_{\text {inh }}$ is the corresponding reference dose through ingestion, dermal contact, and inhalation $(\mathrm{mg} / \mathrm{kg} / \mathrm{d}$, obtained from Ferreira-Baptista and De Miguel, 2005; Jiang et al. 2017; Peng et al., 2017; USEPA, 2016); $C R$ and HQ are total cancer risk and total hazard quotient posed by heavy metals in soil; $\operatorname{InhR}=20 \mathrm{~m}^{3} / \mathrm{d}$ for adults and $7.6 \mathrm{~m}^{3} / \mathrm{d}$ for children (FerreiraBaptista and De Miguel, 2005; USEPA, 2016).

\subsection{Positive matrix factorization model}

Recommended by U.S. Environmental Protection Agency (USEPA, 2014), positive matrix factorization (PMF) has shown good ability of general source apportionment (Jiang et al., 2017; Peng et al., 2017). This study also employed PMF to analyze the possible sources influencing heavy metals in soil. The theory of PMF and input requirements including the determination of uncertainty data refer to guideline of USEPA (2014).

\section{Results and discussion}

\subsection{Soil heavy metal pollution}

The major type of soil samples in the study area was sandy clay loam based on soil texture analysis (data not shown). Soils of the study area were alkaline, with $\mathrm{pH}$ ranging from 7.39 to 10.02 (Table 1). Soil TOC exhibited significant spatial variety, ranging from 0.42 to $76.93 \mathrm{~g} / \mathrm{kg}$ with average value of $10.07 \mathrm{~g} / \mathrm{kg}$.

Heavy metals in soil of the study area showed spatial and element-specific variety (Table 1). The average values of $\mathrm{Hg}$ and $\mathrm{Cd}$ were 0.28 and $0.68 \mathrm{mg} / \mathrm{kg}$ while their maximal concentrations reached 0.80 and $14.84 \mathrm{mg} / \mathrm{kg}$, respectively. The maximal concentrations of $\mathrm{Hg}$ and $\mathrm{Cd}$ in soil exceeded over 40 and 108 times of their background values. $\mathrm{Pb}$ possessed the highest concentrations among all heavy metals with the value of $2076.28 \mathrm{mg} / \mathrm{kg}$. $\mathrm{Zn}, \mathrm{Cr}$, and V illustrated relatively high average concentrations with values of $145.64,93.29$, and $83.10 \mathrm{mg} / \mathrm{kg}$, respectively. Soil quality of about 8.57\% (target metal: Cd)-87.14\% (target metal: $\mathrm{Ni}$ ) of sampling sites was evaluated as Level I based on Environmental Quality Standard For Soils of China (GB15618-1995) that only listed the classification criterion for $\mathrm{Cr}, \mathrm{Ni}, \mathrm{Cu}, \mathrm{Zn}, \mathrm{Cd}$, As (not measured by this study), $\mathrm{Hg}$, and $\mathrm{Pb}$. Accordingly, soil quality of about $10.00 \%$ (target metal: $\mathrm{Ni}$ )-

\begin{tabular}{|c|c|c|c|c|c|c|c|c|c|c|c|c|c|c|}
\hline & V & $\mathrm{Cr}$ & Co & $\mathrm{Ni}$ & $\mathrm{Cu}$ & $\mathrm{Zn}$ & Mo & $\mathrm{Cd}$ & Sn & $\mathrm{Sb}$ & $\mathrm{Hg}$ & $\mathrm{Pb}$ & TOC & $\mathrm{pH}$ \\
\hline Mean & 83.10 & 93.29 & 11.59 & 54.73 & 40.74 & 145.64 & 1.97 & 0.68 & 7.26 & 2.35 & 0.28 & 72.49 & 10.07 & 8.33 \\
\hline SE & 2.00 & 15.17 & 0.91 & 18.54 & 3.84 & 18.46 & 0.57 & 0.22 & 0.14 & 0.20 & 0.02 & 30.53 & 1.85 & 0.06 \\
\hline Minimum & 46.54 & 42.42 & 5.48 & 14.53 & 17.07 & 70.13 & 0.48 & 0.11 & 5.00 & 0.97 & 0.07 & 8.63 & 0.42 & 7.39 \\
\hline Median & 80.23 & 69.52 & 10.18 & 26.76 & 30.35 & 104.98 & 1.14 & 0.29 & 7.17 & 1.93 & 0.19 & 31.07 & 4.59 & 8.27 \\
\hline Maximum & 136.33 & 913.07 & 56.00 & 1015.63 & 253.29 & 1002.39 & 40.68 & 14.84 & 12.35 & 10.25 & 0.80 & 2076.68 & 76.93 & 10.02 \\
\hline
\end{tabular}
72.86\% (target metal: Cd) of sampling sites was evaluated as Level II

Table 1

Statistical summary of $\mathrm{pH}, \mathrm{TOC}$, and heavy metal concentrations of soil samples ( $\mathrm{n}=70, \mathrm{~g} / \mathrm{kg}$ for TOC and mg/kg for all heavy metals).

Note: TOC means total organic carbon; SE means standard error. 
Table 2

Statistical summary of $I_{g e o}$ and $E F$ of soil heavy metals and percentage of classification $(\mathrm{n}=70)$.

\begin{tabular}{|c|c|c|c|c|c|c|c|c|c|c|c|c|}
\hline$I_{\text {geo }}$ & V & $\mathrm{Cr}$ & Co & $\mathrm{Ni}$ & $\mathrm{Cu}$ & $\mathrm{Zn}$ & Mo & $\mathrm{Cd}$ & Sn & $\mathrm{Sb}$ & $\mathrm{Hg}$ & $\mathrm{Pb}$ \\
\hline Mean & -0.40 & -0.48 & -0.53 & -0.54 & 0.07 & -0.01 & -0.01 & 0.83 & 1.26 & -0.08 & 2.87 & 0.07 \\
\hline SE & 0.03 & 0.08 & 0.07 & 0.11 & 0.09 & 0.09 & 0.10 & 0.14 & 0.03 & 0.07 & 0.12 & 0.14 \\
\hline minimum & -1.21 & -1.31 & -1.47 & -1.61 & -0.96 & -0.78 & -1.49 & -0.90 & 0.74 & -1.19 & 1.19 & -1.86 \\
\hline median & -0.42 & -0.60 & -0.57 & -0.73 & -0.13 & -0.20 & -0.25 & 0.48 & 1.26 & -0.19 & 2.68 & -0.01 \\
\hline maximum & 0.34 & 3.12 & 1.89 & 4.52 & 2.93 & 3.06 & 4.91 & 6.17 & 2.04 & 2.22 & 4.74 & 6.05 \\
\hline$I_{g e o}$ class I & $94.3 \%$ & $94.3 \%$ & $91.4 \%$ & $92.9 \%$ & $60.0 \%$ & $70.0 \%$ & $61.4 \%$ & $11.4 \%$ & 1 & $70.0 \%$ & 1 & $52.9 \%$ \\
\hline$I_{g e o}$ class II & $5.7 \%$ & $2.9 \%$ & $5.7 \%$ & $4.3 \%$ & $22.9 \%$ & $22.9 \%$ & $31.4 \%$ & $62.9 \%$ & $8.6 \%$ & $21.4 \%$ & 1 & $38.6 \%$ \\
\hline$I_{g e o}$ class III & 1 & 1 & $2.9 \%$ & 1 & $15.7 \%$ & $2.9 \%$ & $5.7 \%$ & $10.0 \%$ & $90.0 \%$ & $5.7 \%$ & $20.0 \%$ & $4.3 \%$ \\
\hline$I_{\text {geo }}$ class IV & I & $1.4 \%$ & 1 & I & $1.4 \%$ & $2.9 \%$ & 1 & $11.4 \%$ & $1.4 \%$ & $2.9 \%$ & $42.9 \%$ & $1.4 \%$ \\
\hline$I_{g e o}$ class V & i & $1.4 \%$ & I & 1 & 1 & $1.4 \%$ & 1 & $1.4 \%$ & 1 & 1 & $15.7 \%$ & 1 \\
\hline Igeo class VI & I & 1 & I & $2.9 \%$ & I & 1 & $1.4 \%$ & $1.4 \%$ & I & i & $21.4 \%$ & $1.4 \%$ \\
\hline$I_{\text {geo }}$ class VII & 1 & 1 & 1 & 1 & 1 & 1 & 1 & $1.4 \%$ & 1 & 1 & 1 & $1.4 \%$ \\
\hline$E F$ & V & $\mathrm{Cr}$ & Co & $\mathrm{Ni}$ & $\mathrm{Cu}$ & $\mathrm{Zn}$ & Mo & $\mathrm{Cd}$ & Sn & $\mathrm{Sb}$ & $\mathrm{Hg}$ & $\mathrm{Pb}$ \\
\hline Mean & 0.96 & 1.25 & 1.00 & 1.97 & 1.79 & 1.63 & 2.22 & 3.92 & 3.07 & 1.37 & 11.16 & 2.52 \\
\hline SE & 0.02 & 0.29 & 0.12 & 0.82 & 0.30 & 0.29 & 0.83 & 1.28 & 0.09 & 0.13 & 0.89 & 0.90 \\
\hline minimum & 0.63 & 0.62 & 0.43 & 0.36 & 0.64 & 0.71 & 0.41 & 0.80 & 1.64 & 0.45 & 2.90 & 0.42 \\
\hline median & 0.93 & 0.81 & 0.81 & 0.77 & 1.07 & 1.05 & 1.03 & 1.78 & 2.93 & 1.04 & 8.20 & 1.18 \\
\hline maximum & 1.45 & 15.71 & 6.69 & 41.94 & 20.04 & 19.07 & 58.61 & 88.84 & 5.58 & 7.17 & 32.20 & 59.23 \\
\hline$E F$ class I & $100.0 \%$ & $97.1 \%$ & $97.1 \%$ & $97.1 \%$ & $81.4 \%$ & $90.0 \%$ & $84.3 \%$ & $60.0 \%$ & $1.4 \%$ & $88.6 \%$ & 1 & $90.0 \%$ \\
\hline$E F$ class II & 1 & 1 & 1 & 1 & $12.9 \%$ & $4.3 \%$ & $11.4 \%$ & $27.1 \%$ & $95.7 \%$ & $8.6 \%$ & $15.7 \%$ & $5.7 \%$ \\
\hline EF class III & 1 & $2.9 \%$ & $2.9 \%$ & 1 & $4.3 \%$ & $5.7 \%$ & $2.9 \%$ & $10.0 \%$ & $2.9 \%$ & $2.9 \%$ & $70.0 \%$ & $1.4 \%$ \\
\hline$E F$ class IV & I & 1 & 1 & 1 & $1.4 \%$ & 1 & 1 & $1.4 \%$ & 1 & 1 & $14.3 \%$ & $1.4 \%$ \\
\hline$E F$ class $\mathrm{V}$ & I & 1 & I & $2.9 \%$ & 1 & i & $1.4 \%$ & $1.4 \%$ & 1 & I & 1 & $1.4 \%$ \\
\hline
\end{tabular}

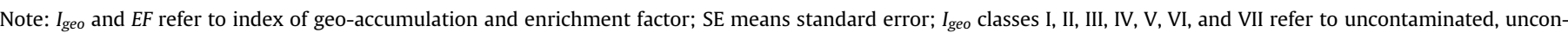

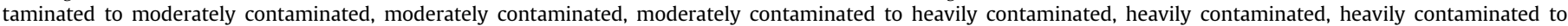

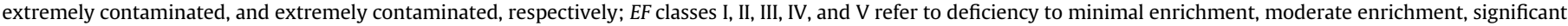
enrichment, very high enrichment, and extremely high enrichment.

while that of about $0.00 \%$ (target metal: $\mathrm{Hg}$ )-18.57\% (target metal: Cd) of sampling sites was evaluated as Level III or worse.

Heavy metal pollution was evaluated by four methods (Table 2 and Fig. 1). Average $I_{g e o}$ values ranged from $-0.54(\mathrm{Ni})$ to 2.87
$(\mathrm{Hg})$ while the minimal and maximal $I_{\text {geo }}$ values were $-1.86(\mathrm{~Pb})$ and $6.17(\mathrm{Cd})$, respectively (Table 1). Based on classification criterion (Ćujić et al., 2016; Tian et al., 2016; Wen et al., 2017; Zhang et al., 2017), heavy metals including V, Cr, Co, and Ni showed the
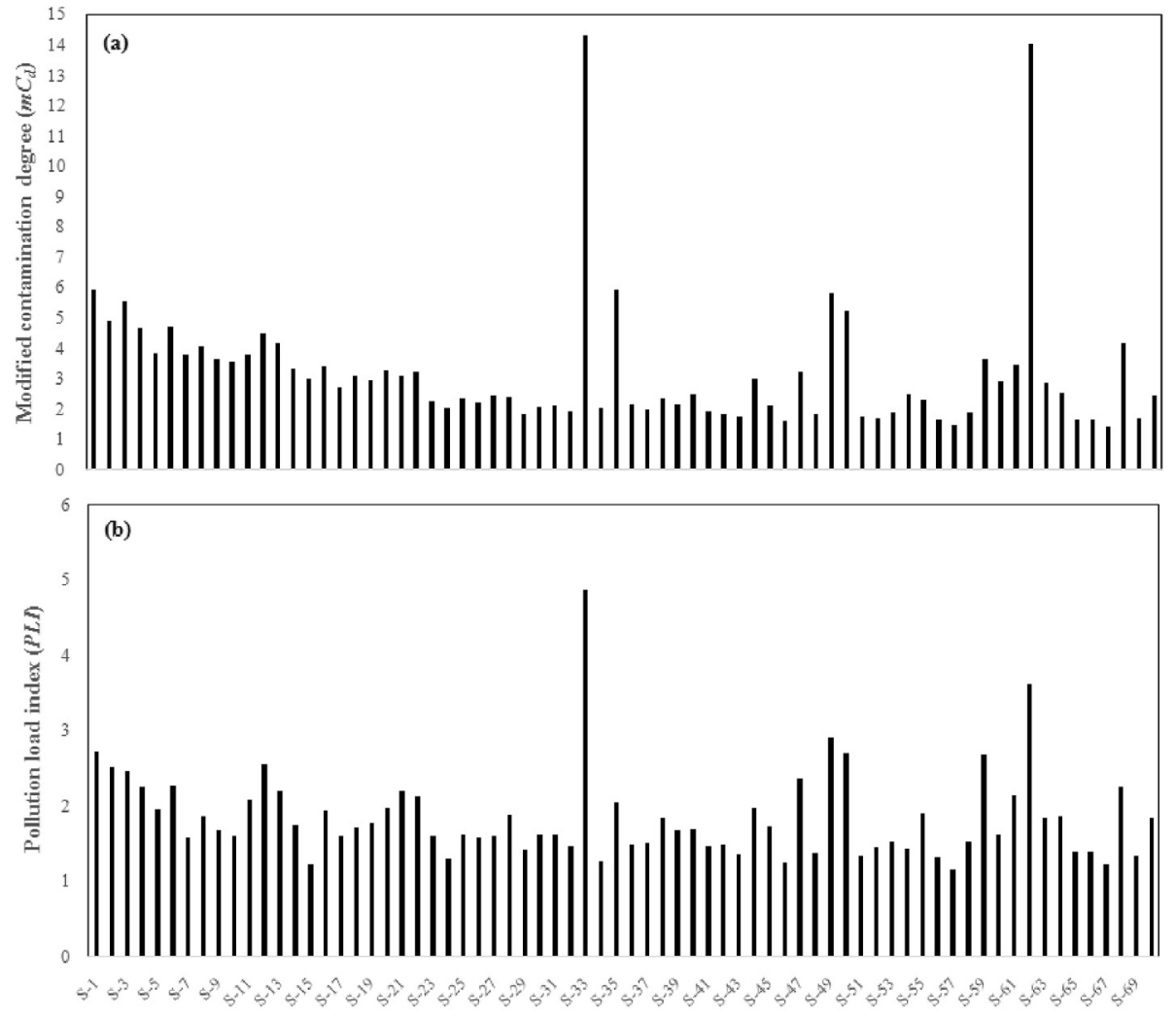

Fig. 1. Modified contamination degree $\left(m C_{d}\right)$ and pollution load index $(P L I)$ of soil heavy metals in the sampling sites. 


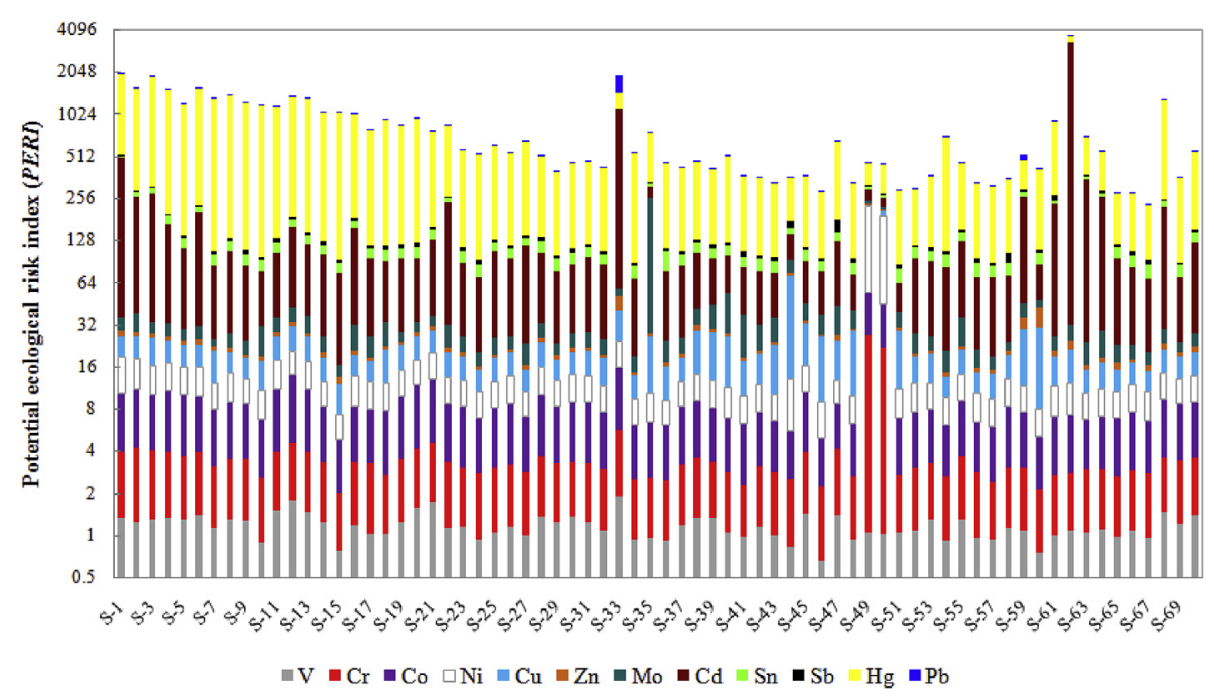

Fig. 2. Potential ecological risks of soil heavy metals in the sampling sites.

similar contamination degree that over $90 \%$ of samples were classified into uncontaminated status while $\mathrm{Cu}, \mathrm{Zn}, \mathrm{Mo}$, and $\mathrm{Sb}$ exhibited the similar patterns with classification of uncontamination/uncontamination to moderate contamination percentages of $60.0 \% / 22.9 \%, 70.0 \% / 22.9 \%, 61.4 \% / 31.4 \%$, and $70.0 \% / 21.4 \%$, respectively. Interestingly, $\mathrm{Cd}, \mathrm{Sn}, \mathrm{Hg}$, and $\mathrm{Pb}$ showed different contamination patterns. Sn mainly posed moderate contamination while Cd exerted uncontamination to moderate contamination, moderate contamination, and moderate contamination to heavy contamination in soils with percentages of $62.9 \%, 10.0 \%$, and $11.4 \%$, respectively. $\mathrm{Pb}$ in soils mainly showed uncontamination (52.9\%) and uncontamination to moderate contamination (38.6\%). $\mathrm{Hg}$ in soils illustrated the most serious contamination among all heavy metals with percentages of $20.0 \%, 42.9 \%, 15.7 \%$, and $21.4 \%$ for
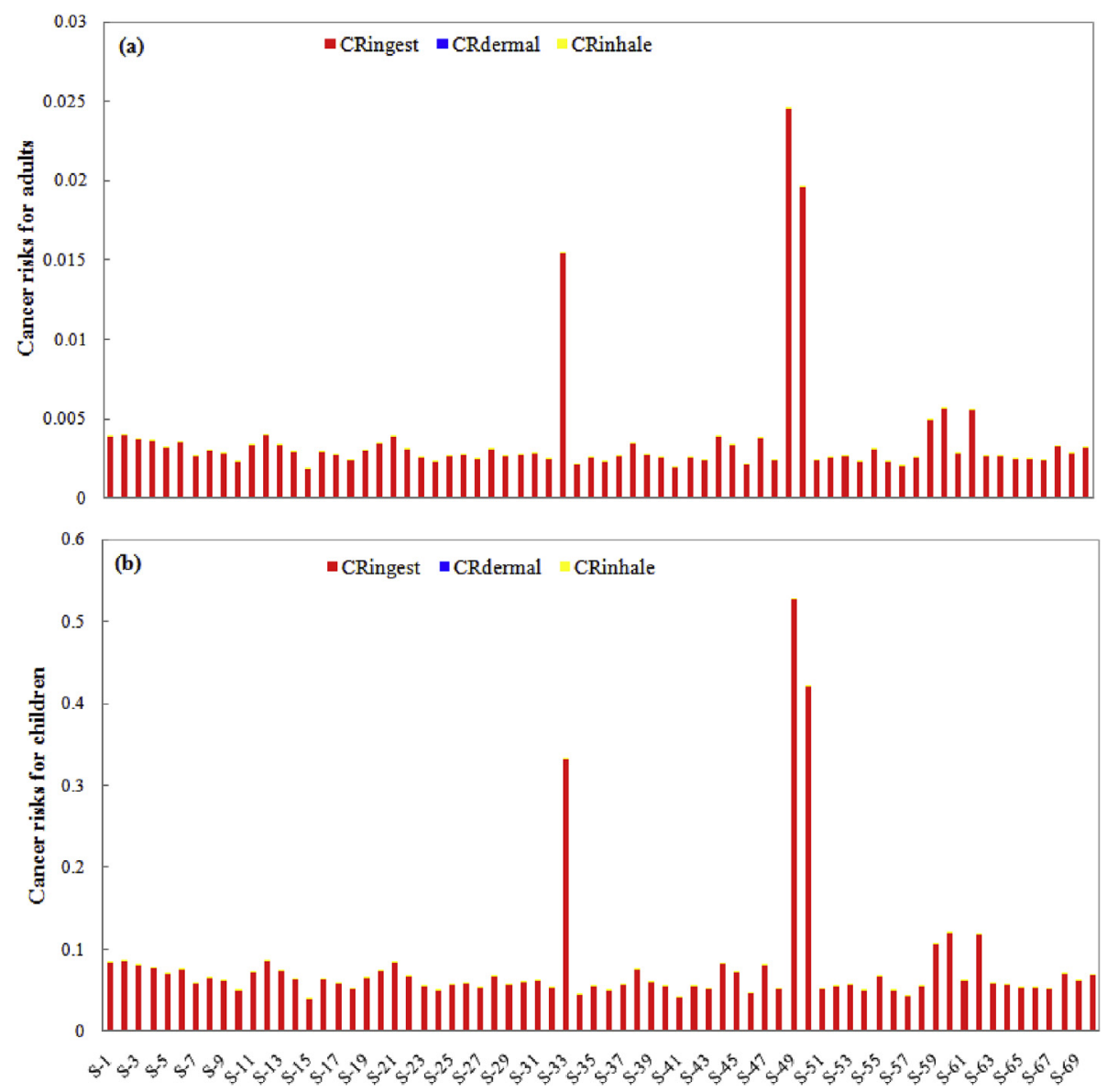

Fig. 3. Cancer risks of soil heavy metals in the sampling sites. 
moderate contamination, moderate contamination to heavy contamination, heavy contamination, and heavy contamination to extreme contamination.

Soil $E F$ values ranged from $0.36(\mathrm{Ni})$ to $88.84(\mathrm{Cd})$ while average values were in the range of $0.96(\mathrm{~V})$ to $11.16(\mathrm{Hg})$, illustrating significant spatial variety (Table 1 ). $\mathrm{V}, \mathrm{Cr}, \mathrm{Co}, \mathrm{Ni}, \mathrm{Cu}, \mathrm{Zn}, \mathrm{Mo}, \mathrm{Sb}$, and $\mathrm{Pb}$ in soils showed the slight enrichment while $\mathrm{Sn}$ in soils illustrated moderate enrichment based on criterion (Ćujić et al., 2016; Wen et al., 2017). Cd in soils exhibited different enrichment patterns with $60.0 \%$ of minimal enrichment, $27.1 \%$ of moderate enrichment, and $10.0 \%$ of significant enrichment while $\mathrm{Hg}$ in soils illustrated $15.7 \%$ of moderate enrichment, $70.0 \%$ of significant enrichment, and $14.3 \%$ of very high enrichment, showing significant enrichment feature. Interestingly, Cd in soil sample collected from S-62 showed the highest $I_{G e o}$ and $E F$ values while several metals such as $S n$ and $\mathrm{Hg}$ did not exhibit similar pattern. For example, $\mathrm{Sn}$ in soil sample from S-36 and $\mathrm{Hg}$ in sample from S-3 possessed the highest $I_{G e o}$ values of 2.04 and 4.74 while $\mathrm{Sn}$ in sample from S-60 and $\mathrm{Hg}$ in sample from S-15 showed the maximal $E F$ values of 5.58 and 32.20 , respectively. These results suggested that soil pollution by individual heavy metal of the study area should be caused by multiple factors besides metal enrichment degree.

Contamination degrees of heavy metals in soil were unexpectedly high (Fig. 1a). Only 2 and 16 sampling sites were in the status of nil to very low contamination degree (when $m C_{d}<1.5$ according to
Abrahim and Parker, 2008) and low contamination degree (when $1.5 \leq m C_{d}<2$ ), respectively. The numbers of sampling sites were respectively 12 and 2 for high degree of contamination (when $\left.4 \leq m C_{d}<8\right)$ and very high contamination degree $\left(8 \leq m C_{d}<16\right)$. The remaining 38 sites showed moderate degree of contamination (when $2 \leq m C_{d}<4$ ). $\mathrm{Hg}, \mathrm{Cd}$, and Sn contributed to main $m C_{d}$ in many sites while $\mathrm{Pb}, \mathrm{Mo}$, and $\mathrm{Zn}$ were the dominant contributors of $m C_{d}$ in several sites.

Based on PLI evaluation criterion (Ćujić et al., 2016; Tian et al., 2017), 51 sampling sites showed moderate contamination degree (when $1<P L I \leq 2$ ) while 19 sites were in the high contamination status (when $2<P L I \leq 5$ ) (Fig. $1 \mathrm{~b}$ ). Compared with $m C_{d}$, PLI evaluation results narrowed the pollution range by weakening the extreme results. Generally, the study area is experiencing provoking heavy metal pollution according to both $m C_{d}$ and $P L I$ evaluation results, more serious than the previous studies (Wu et al., 2016a).

\subsection{Ecological risks of heavy metals in soil}

Ecological risk indexes of heavy metals in soil ranged from 234.6 to 3759.0 (Fig. 2). It is surprising that all sampling sites possessed relatively high ecological risks based on the classification criterion (Madiseh et al., 2009; Ke et al., 2017). About 6 out of 70 sampling sites exhibited moderate ecological risks (when $150 \leq P E R I<300$ ) while half of the remaining sites showed considerable ecological
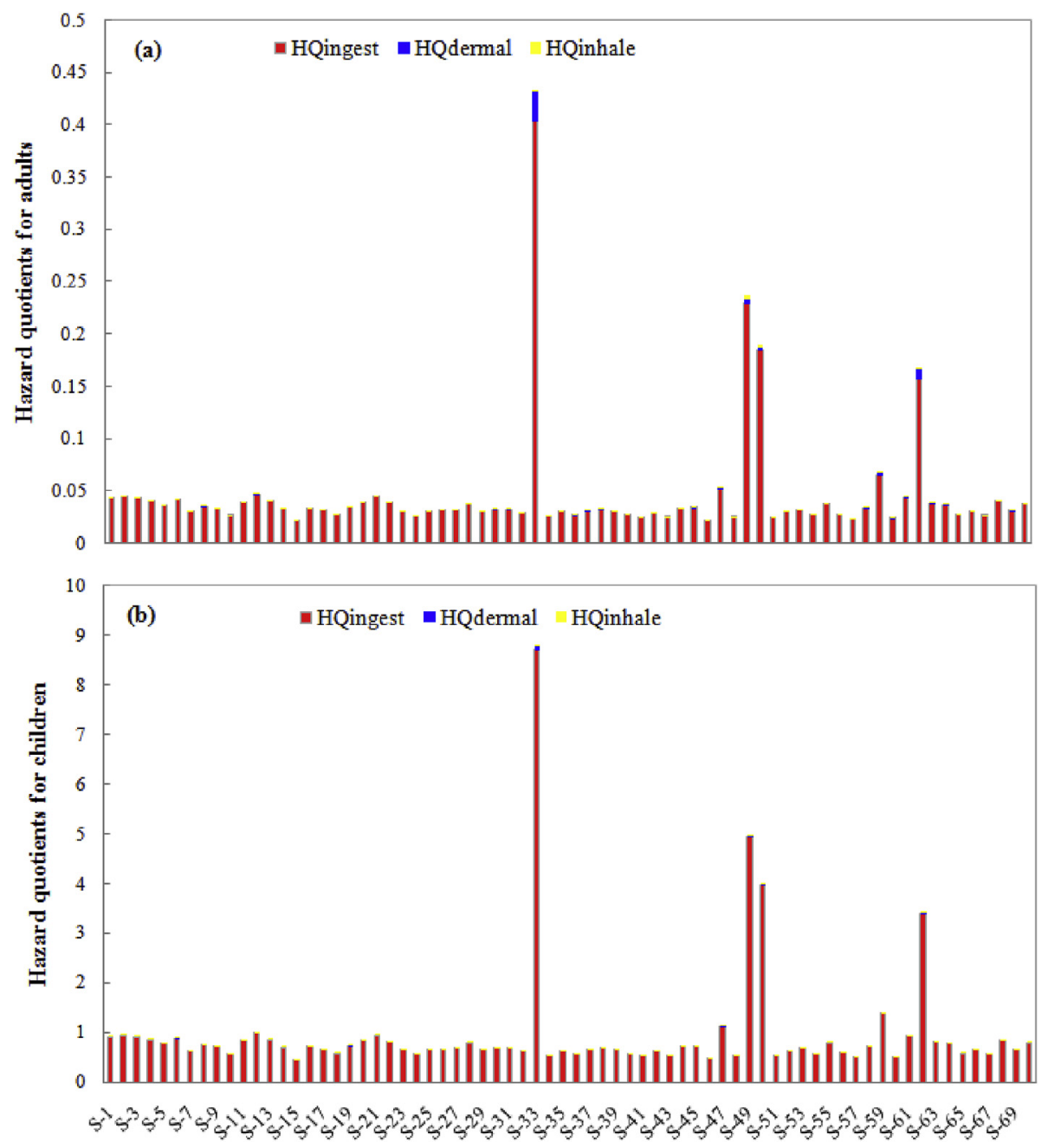

Fig. 4. Non-cancer risks of soil heavy metals in the sampling sites. 
risks (when $300 \leq P E R I<600$ ) and the other 32 sites possessed very high ecological risks (when $P E R I \geq 600$ ). Serving as the dominant ecological-risk factor, $\mathrm{Hg}$ contributed over $50 \%$ ecological risks to 64 sampling sites with contribution percentage ranging from $50.7 \%$ to 91.6\%. Ecological risks deriving from $\mathrm{Hg}$ ranged from 136.57 to 1602.95. Cd was the second dominant ecological-risk factor with the maximal contribution percentage of $86.4 \%$. The highest PERI contribution percentages of $\mathrm{V}, \mathrm{Co}, \mathrm{Sb}, \mathrm{Sn}$, and $\mathrm{Cr}$ ranged from $0.41 \%$ (V) to $7.76 \%(\mathrm{Sn})$. Ecological risks deriving from Sn ranged from 12.50 to 30.88 . For several sites, contributions of $\mathrm{Ni}, \mathrm{Cu}, \mathrm{Mo}$, and $\mathrm{Pb}$ were also high with the maximal contribution percentages of $36.7 \%, 15.7 \%, 29.6 \%$, and $25.8 \%$, respectively. Ecological risks exerted by heavy metals in soil reached considerably high level in the study area to deserve urgent and effective pollution control.

\subsection{Health risks posed by heavy metals in soil}

Cancer risks $(C R)$ of heavy metals for adults and children were in the ranges of $1.91 \times 10^{-3}-2.46 \times 10^{-2}$ and $4.09 \times 10^{-2}-5.29 \times 10^{-1}$, respectively (Fig. 3). Cancer risks for children were generally over 20 times higher than those for adults, suggesting that children are much more susceptible to adverse effects of soil heavy metals. The cancer risks through pathways of ingestion, dermal contact, and inhalation followed the order of $C R_{\text {inhale }}<C R_{\text {dermal }}<<C R_{\text {ingest }}$. Risks of heavy metals through ingestion accounted for over $99.1 \%$ of cancer risks while risks through dermal contact were usually over 20 times higher than those through inhalation. $\mathrm{Cr}$ was the dominant contributor for the cancer risks through ingestion, with the highest contribution percentages of $92.7 \%$ for both adults and

(a)

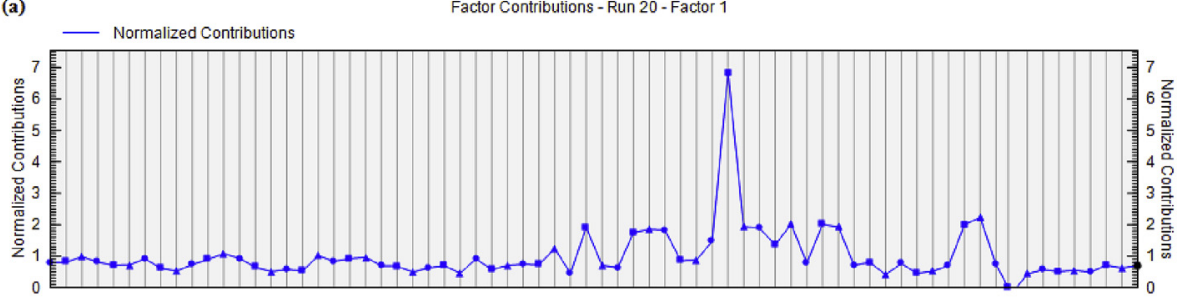

(b)

Factor Contributions - Run 20 - Factor 2

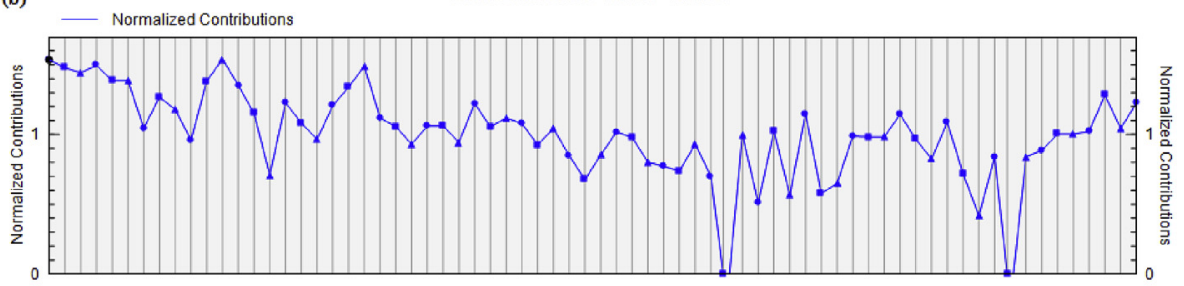

(c)
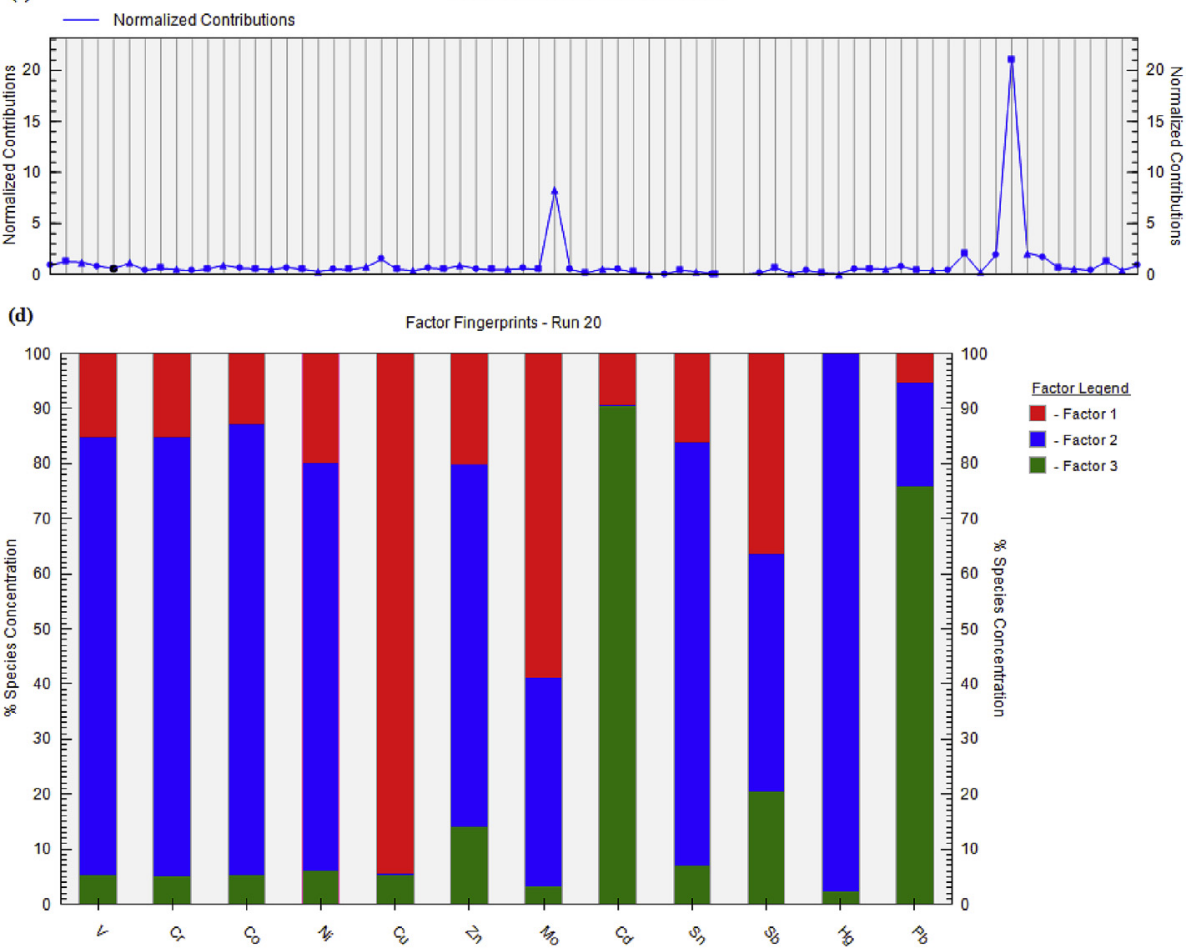

Fig. 5. Factor normalized contributions and factor fingerprint. 
children (Fig. S2). Zn, V, Pb, Cu, and Co also contributed to cancer risks through ingestion to relatively significant extent. $\mathrm{Zn}$ served as the main contributor for the cancer risks through dermal contact, and then followed by $\mathrm{Pb}$ and $\mathrm{Cu}$. $\mathrm{Cr}$ and $\mathrm{Zn}$ mainly accounted for the cancer risks through inhalation, similar with those through ingestion. Based on the screening criterion (Ge et al., 2013), cancer risks for adults of all sites were evaluated as high (when $1 \times 10^{-3}<C R \leq 1 \times 10^{-1}$ ). Correspondingly, there were 6 and 64 sites to illustrate very high and high cancer risks for children, respectively.

The total hazard quotients of soil heavy metals for adults and children were in the ranges of $0.023-0.434$ and $0.466-8.815$ with the average value of 0.048 and 0.987 , respectively (Fig. 4). Hazard quotients for adults were less than threshold of 1.0, suggesting the non-cancer risks for adults were low. However, hazard quotients for children in 68 sites exceeded 0.500 and those in 7 sites exceeded 1.0 with maximal value of 8.815 , suggesting the high non-cancer risks for children in the study area. Non-cancer risks through ingestion accounted for over $99.2 \%$ and $98.5 \%$ of the total risks for adults and children, respectively (Fig. S3). Non-cancer risks through dermal contact in most of sites were 2-6 times higher than those through inhalation with the maximal ratio over 38 and 40 for adults and children. Total hazard quotients for children were 20 times higher than those for adults, also suggesting that children are more susceptible to potential hurt from heavy metals in soil. $\mathrm{Cr}$ was the dominant contributor for the non-cancer risks through ingestion, and then followed by $\mathrm{Pb} . \mathrm{V}, \mathrm{Ni}, \mathrm{Sb}$, and $\mathrm{Hg}$ also contributed to noncancer risks through ingestion. $\mathrm{Pb}, \mathrm{V}, \mathrm{Cr}, \mathrm{Sb}$, and $\mathrm{Hg}$ served as the main contributors for the non-cancer risks through dermal contact. Different from cancer risks, $\mathrm{Cr}$ and Co accounted for over $92.8 \%$ of non-cancer risks through inhalation. The difference in dominant contribution heavy metals for cancer and non-cancer risks through 3 pathways exhibited the different toxicity mechanism of heavy metals.

\subsection{Possible sources of heavy metals in soil}

After screening by PMF model, 3 factors with corresponding contributions were determined for the possible sources of heavy metals in soil (Fig. 5). Comparing the dominant heavy metals of each factor and the background information of the study area, the possible sources were determined as industry (factor 2), mining (factor 1), and transport and agriculture (factor 3). Potential ecological and health risks of 3 factors were evaluated, respectively (Figs. S4-S6). PERI values of factor 1, factor 2, and factor 3 were in the ranges of $16.7-344.9,161.8-1607.6,32.9-3077.2$, respectively, with the order of factor $1<$ factor $3<$ factor 2 for most of the sites (Fig. S4). Cr was the dominant contributors for PERI of factor 1 and 3 while Hg was the dominant contributor for that of factor 2. Cancer risks of factor 1 , factor 2 , and factor 3 for adults/children were in the ranges of $3.65 \times 10^{-4}-3.88 \times 10^{-3} / 7.83 \times 10^{-3}-8.35 \times 10^{-2}, 1.34$ $\times 10^{-3}-1.93 \times 10^{-2} / 2.88 \times 10^{-2}-4.16 \times 10^{-1}$, and $1.77 \times 10^{-4}$ $-6.68 \times 10^{-3} / 3.79 \times 10^{-3}-1.43 \times 10^{-1}$, respectively (Fig. S5). Cancer risks of three factors followed the order of factor $3<$ factor $1<$ factor 2. Hazard quotients of factor 1 , factor 2 , and factor 3 for adults/children were in the ranges of $3.53 \times 10^{-3}-3.88$ $\times 10^{-2} / 7.33 \times 10^{-2}-8.13 \times 10^{-1}, \quad 1.42 \times 10^{-2}-1.82 \times 10^{-1} / 2.95 \times$ $10^{-1}-3.82$, and $3.31 \times 10^{-3}-2.95 \times 10^{-1} / 6.79 \times 10^{-2}-5.97$, respectively (Fig. S6). Similar with PERI, non-cancer risks of three factors followed the order of factor $1<$ factor $3<$ factor 2 for most of the sites, suggesting the difference in the toxicity mechanisms of heavy metals for cancer and non-cancer risks.

\section{Conclusions}

Heavy metal pollution of soils in the study area was serious. $\mathrm{Pb}$ possessed the highest concentrations while the maximal concentrations of $\mathrm{Hg}$ and $\mathrm{Cd}$ in soil were over 40 times higher than their background values. Hg caused the most serious pollution according to $I_{\text {geo }}$ results and also showed the strong enrichment features. Based on $m C_{d}$ evaluation results, about $54.3 \%, 17.1 \%$, and $2.9 \%$ of sampling sites showed moderate, high, and very high contamination degree, respectively. Accordingly, pollution load index results illustrated $72.9 \%$ and $27.1 \%$ of sampling sites possessed moderate and high contamination level, respectively. Consequently, ecological risk indexes posed by heavy metals in soil ranged from 234.6 to 3759.0 , suggesting that most of sites were under considerable/very high risks. Cancer risks/hazard quotients of heavy metals for adults and children were in the ranges of $1.91 \times 10^{-3}-2.46 \times 10^{-2}$ / $0.023-0.434$ and $4.09 \times 10^{-2}-5.29 \times 10^{-1} / 0.466-8.815$, respectively. Cancer risks for adults and children were determined as high and high-very high levels while non-cancer risks for children were high although those for adults seemed low. Three possible sources were determined by PMF model and industrial source contributed to main part of ecological and health risks. In summary, the northeastern Qinghai-Tibet Plateau has endured the serious heavy metal pollution to exert high potential ecological and health risks, especially for children. Therefore, more efficient and strict pollution control and management should be put out as soon as possible.

\section{Acknowledgements}

This work was supported by National Natural Science Foundation of China (No. 41671319), One Hundred-Talent Plan of Chinese Academy of Sciences (Grant numbers of Y610061033 and Y629041021), Thousand Talents Plan of Qinghai Province (Y740171071), and Two-Hundred Talents Plan of Yantai (Y739011021). The authors would like to thank the reviewers for their valuable suggestions and comments on the manuscript.

\section{Appendix A. Supplementary data}

Supplementary data related to this article can be found at https://doi.org/10.1016/j.chemosphere.2018.02.122.

\section{References}

Abrahim, G.M.S., Parker, R.J., 2008. Assessment of heavy metal enrichment factors and the degree of contamination in marine sediments from Tamaki Estuary, Auckland, New Zealand. Environ. Monit. Assess. 136, 227-238.

Bhuiyan, M.A.H., Parvez, L., Islam, M.A., Dampare, S.B., Suzuki, S., 2010. Heavy metal pollution of coal mine-affected agricultural soils in the northern part of Bangladesh. J. Hazard Mater. 173, 384-392.

Bing, H., Wu, Y., Zhou, J., Ming, L., Sun, S., Li, X., 2014. Atmospheric deposition of lead in remote high mountain of eastern Tibetan Plateau, China. Atmos. Environ. 99, 425-435.

Burges, A., Epelde, L., Garbisu, C., 2015. Impact of repeated single-metal and multimetal pollution events on soil quality. Chemosphere 120, 8-15.

Chester, R., Stoner, J.H., 1973. Pb in particulates from the lower atmosphere of the eastern Atlantic. Nature 245, 27-28.

Clark, E.V., Odhiambo, B.K. Ricker, M.C., 2014. Comparative analysis of metal concentrations and sediment accumulation rates in two virginian reservoirs, USA: lakes Moomaw and Pelham. Water Air Soil Pollut. 225 (2), 1-18.

Ćujić, M., Dragović, S., Đorđević, M., Dragović, R., Gajić, B., 2016. Environmental assessment of heavy metals around the largest coal fired power plant in Serbia. Catena 139, 44-52.

Ferreira-Baptista, L., De Miguel, E., 2005. Geochemistry and risk assessment of street dust in Luanda, Angola: a tropical urban environment. Atmos. Environ. 39, 4501-4512.

Ge, J., Woodward, L.A., Li, Q.X., Wang, J., 2013. Composition, distribution and risk assessment of organochlorine pesticides in soils from the Midway Atoll, North Pacific Ocean. Sci. Total Environ. 452-453, 421-426. 
Hakanson, L., 1980. An ecological risk index for aquatic pollution control, a sedimentological approach. Water Res. 14, 975-1001.

Huang, X., Sillanpää, M., Duo, B., Gjessing, E.T., 2008. Water quality in the Tibetan Plateau: metal contents of four selected rivers. Environ. Pollut. 156, 270-277. Järup, L., 2003. Hazards of heavy metal contamination. Br. Med. Bull. 68, 167-182.

Jiang, Y., Chao, S., Liu, J., Yang, Y., Chen, Y., Zhang, A., Cao, H., 2017. Source apportionment and health risk assessment of heavy metals in soil for a township in Jiangsu Province, China. Chemosphere 168, 1658-1668.

Ke, X., Gui, S., Huang, H., Zhang, H., Wang, C., Guo, W., 2017. Ecological risk assessment and source identification for heavy metals in surface sediment from the Liaohe River protected area, China. Chemosphere 175, 473-481.

Kowalska, J., Mazurek, R., Gąsiorek, M., Setlak, M., Zaleski, T., Waroszewski, J., 2016. Soil pollution indices conditioned by medieval metallurgical activity e A case study from Krakow (Poland). Environ. Pollut. 218, 1023-1036.

Liang, J., Feng, C., Zeng, G., Gao, X., Zhong, M., Li, X., Li, X., He, X., Fang, Y., 2017. Spatial distribution and source identification of heavy metals in surface soils in a typical coal mine city, Lianyuan, China. Environ. Pollut. 225, 681-690.

Madiseh, S.D., Savary, A., Parham, H., Sabzalizadeh, S., 2009. Determination of the level of contamination in Khuzestan coastal waters (Northern Persian Gulf) by using an ecological risk index. Environ. Monit. Assess. 159, 521-530.

Ministry of Environmental Protection of the People's Republic of China (MEPC), 1990. Background Values of Soil Elements in China. China Environment Science Press, Beijing, pp. 329-493.

Müller, G., 1969. Index of geo-accumulation in sediments of the Rhine river. Geojournal 2 (3), 108-118.

Oves, M., Khan, M.S., Zaidi, A., Ahmad, E., 2012. Soil contamination, nutritive value, and human health risk assessment of heavy metals: an overview. In: Zaidi, A. Wani, P.A., Khan, M.S. (Eds.), Toxicity of Heavy Metals to Legumes and Bioremediation. Springer, Wien, pp. 1-27.

Padoan, E., Romè, C., Ajmone-Marsan, F., 2017. Bioaccessibility and size distribution of metals in road dust and roadside soils along a peri-urban transect. Sci. Total Environ. 601-602, 89-98.

Pan, L., Ma, J., Wang, X., Hou, H., 2016. Heavy metals in soils from a typical county in Shanxi Province, China: levels, sources and spatial distribution. Chemosphere $148,248-254$

Peng, X., Shi, G., Liu, G., Xu, J., Tian, Y., Zhang, Y., YinChang Feng, Y., Russell, A.G., 2017. Source apportionment and heavy metal health risk (HMHR) quantification from sources in a southern city in China, using an ME2-HMHR model. Environ. Pollut. 221, 335-342.

Rachwał, M., Kardel, K., Magiera, T., Bens, O., 2017. Application of magnetic susceptibility in assessment of heavy metal contamination of Saxonian soil (Germany) caused by industrial dust deposition. Geoderma 295, 10-21.

Rovira, J., Mari, M., Nadal, M., Schuhmacher, M., Domingo, J.L., 2010. Environmental monitoring of metals, PCDD/Fs and PCBs as a complementary tool of biological surveillance to assess human health risks. Chemosphere 80, 1183-1189.

Sakai, N., Alsaad, Z., Thuong, N.T., Shiota, K., Yoneda, M., Mohd, M.A., 2017. Source profiling of arsenic and heavy metals in the Selangor River basin and their maternal and cord blood levels in Selangor State, Malaysia. Chemosphere 184, $857-865$

Salmanighabeshi, S., Palomo-Marín, M.R., Bernalte, E., Rueda-Holgado, F., MiróRodríguez, C., Fadic-Ruiz, X., Vidal-Cortez, V., Cereceda-Balic, F., Pinilla-Gil, E., 2015. Long-term assessment of ecological risk from deposition of elemental pollutants in the vicinity of the industrial area of Puchuncaví-Ventanas, central
Chile. Sci. Total Environ. 527, 335-343.

Sheng. J. Wang X, Gong. P. Tian, L., Yao, T, 2012. Heavy metals of the Tibetan top soils-Level, source, spatial distribution, temporal variation and risk assessment. Environ. Sci. Pollut. Res. 19, 3362-3370.

Sultana, J., Syed, J.H., Mahmood, A., Ali, U., Rehman, M.Y., Malik, R.N., Li, J., Zhang, G., 2014. Investigation of organochlorine pesticides from the Indus Basin, Pakistan: sources, air-soil exchange fluxes and risk assessment. Sci. Total Environ. 497-498, 113-122.

Tepanosyan, G., Sahakyan, L., Belyaeva, O., Maghakyan, N., Saghatelyan, A., 2017a. Human health risk assessment and riskiest heavy metal origin identification in urban soils of Yerevan, Armenia. Chemosphere 184, 1230-1240.

Tepanosyan, G., Maghakyan, N., Sahakyan, L., Armen Saghatelyan, A., 2017b. Heavy metals pollution levels and children health risk assessment of Yerevan kindergartens soils. Ecotoxicol. Environ. Saf. 142, 257-265.

Tian, K., Hu, W., Xing, Z., Huang, B., Jia, M., Wan, M., 2016. Determination and evaluation of heavy metals in soils under two different greenhouse vegetable production systems in eastern China. Chemosphere 165, 555-563.

Tian, K., Huang, B., Xing, Z., Hu, W., 2017. Geochemical baseline establishment and ecological risk evaluation of heavy metals in greenhouse soils from Dongtai, China. Ecol. Indicat. 72, 510-520.

USEPA (U.S. Environmental Protection Agency), 2014. EPA Positive Matrix Factorization (PMF) 5.0 Fundamentals and User Guide. EPA/600/R-14/108.

USEPA (U.S. Environmental Protection Agency), 2016. Regional Screening Levels (RSLs) - User's Guide available on. https://www.epa.gov/risk/regionalscreening-levels-rsls-users-guide-may-2016.

Wen, X., Wang, Q., Zhang, G., Bai, J., Wang, W., Zhang, S., 2017. Assessment of heavy metals contamination in soil profiles of roadside Suaeda salsa wetlands in a Chinese delta. Phys. Chem. Earth 97, 71-76.

Wu, J., Duan, D., Lu, J., Luo, Y., Wen, X., Guo, X., Boman, B.J., 2016a. Inorganic pollution around the Qinghai-Tibet Plateau: an overview of the current observations. Sci. Total Environ. 550, 628-636.

Wu, J., Lu, J., Luo, Y., Duan, D., Zhang, Z., Wen, X., Min, X., Guo, X., Boman, B.J., 2016b. An overview on the organic pollution around the Qinghai-Tibet plateau: the thought-provoking situation. Environ. Int. 97, 264-272.

Xiao, R., Wang, S., Li, R., Wang, J.J., Zhang, Z., 2017. Soil heavy metal contamination and health risks associated with artisanal gold mining in Tongguan, Shaanxi, China. Ecotoxicol. Environ. Saf. 141, 17-24.

Yang, R., Yao, T., Xu, B., Jiang, G., Xin, X., 2007. Accumulation features of organochlorine pesticides and heavy metals in fish from high mountain lakes and Lhasa River in the Tibetan Plateau. Environ. Int. 33, 151-156.

Yang, R., Jing, C., Zhang, Q., Wang, Z., Wang, Y., Li, Y., Jiang, G., 2011. Polybrominated diphenyl ethers (PBDEs) and mercury in fish from lakes of the Tibetan Plateau. Chemosphere 83, 862-867.

Zhang, H., Zhang, Y., Wang, Z., Ding, M., 2013. Heavy metal enrichment in the soil along the Delhi-Ulan section of the Oinghai-Tibet railway in China. Environ. Monit. Assess. 185, 5435-5447.

Zhang, G., Bai, J., Xiao, R., Zhao, Q., Jia, J., Cui, B., Liu, X., 2017. Heavy metal fractions and ecological risk assessment in sediments from urban, rural and reclamationaffected rivers of the Pearl River Estuary, China. Chemosphere 184, 278-288.

Zhu, L., Liu, J., Xu, S., Xie, Z., 2017. Deposition behavior, risk assessment and source identification of heavy metals in reservoir sediments of Northeast China. Ecotoxicol. Environ. Saf. 142, 454-463. 